\title{
PENGEMBANGAN UNIT PELATIHAN TEKNOLOGI INFORMASI DI POLITEKNIK NEGERI BANDUNG
}

\author{
Ghifari Munawar ${ }^{1}$, Bambang Wisnuadhi ${ }^{1}$, Lukmanul Hakim Firdaus ${ }^{1}$, Aprianti Nanda \\ Sari $^{1}$, Cholid Fauzi ${ }^{1}$, Siti Dwi Setiarini ${ }^{1}$, Trisna Gelar Abdillah ${ }^{1}$ \\ ${ }^{1}$ Jurusan Teknik Komputer dan Informatika, Politeknik Negeri Bandung \\ Email: ghifari.munawar@polban.ac.id
}

\begin{abstract}
Abstrak
Berdasarkan data dari Badan Pusat Statistik (BPS), tingkat pengangguran tahun 2019 untuk lulusan SMK merupakan angka paling tinggi dibanding jenjang pendidikan lainnya. Hal ini terjadi karena keterampilan lulusan SMK belum sepenuhnya sesuai dengan kebutuhan industri. Untuk itu, perlu adanya unit pelatihan teknologi informasi di perguruan tinggi yang bidangnya bersesuaian sebagai wadah para lulusan SMK yang belum bekerja untuk meningkatkan kemampuan mereka agar dapat diterima di industri. Selain itu, unit pelatihan teknologi informasi di perguruan tinggi juga dapat menjadi sarana dosen untuk melaksanakan pengabdian kepada masyarakat dengan menjadi instruktur pada pelatihan tersebut. Metode pelaksanaan yang dilakukan dalam pengabdian masyarakat ini antara lain studi literatur, pengumpulan data, analisa kebutuhan, perencanaan pembuatan unit pelatihan, dan pembuatan media promosi. Luaran lain dari program ini adalah terbentuknya dokumen kurikulum pelatihan dan bahan ajar yang sesuai dengan kompetensi SKKNI yang diharapkan dan sesuai dengan kebutuhan industri, sehingga angkatan kerja lulusan SMK dapat terserap dengan baik.
\end{abstract}

Kata kunci: Pengembangan Unit Pelatihan, SMK, Pelatihan, Lulusan SMK

\section{PENDAHULUAN}

Berdasarkan data dari Badan Pusat Statistik (BPS), tingkat pengangguran di tahun 2019 menyatakan bahwa lulusan Sekolah Menengah Kejuruan (SMK) merupakan angka paling tinggi dibandingkan lulusan pada jenjang pendidikan lainnya [1]. Menurut hasil penelitian lembaga Institute for Development of Economocs and Finance (INDEF), tingginya angka pengangguran tersebut ter jadi karena skill lulusan SMK tidak sesuai dengan kebutuhan industri [2]. Untuk mengatasi permasalahan ini, beberapa SMK telah menganjurkan lulusannya yang belum bekerja untuk mengikuti pelatihan tambahan dan sertifikasi yang sesuai bidang, salah satunya adalah bidang Teknik Komputer dan Jaringan (TKJ), Rekayasa Perangkat Lunak (RPL) dan Multimedia dikarenakan tingginya kebutuhan industri pada bidang ini. 
Dari peluang tersebut, maka perlu adanya pembentukan unit pelatihan di perguruan tinggi yang bidangnya bersesuaian dengan bidang di SMK. Salah satu jurusan di Politeknik Negeri Bandung (Polban) yang memiliki keahlian pada bidang TKJ, RPL dan Multimedia adalah Jurusan Teknik Komputer dan Informatika (JTK). JTK telah memiliki pengalaman dengan menyelenggarakan pelatihan VSGA (Vocational School Graduate Academy) di tahun 2019 yang bekerjasama dengan Kominfo sebagai mitranya, dimana hasil dari pelatihan ini $89 \%$ peserta lulus sertifikasi LSP. Berdasarkan hasil tersebut terdapat potensi besar untuk dikembangkannya sebuah unit pelatihan teknologi informasi di JTK. Penguatan keterampilan yang akan diberikan tidak hanya memperhatikan aspek hard skill saja namun juga aspek soft skill nya, dimana salah satunya adalah kemampuan problem solving. Hal ini sesuai dengan keterampilan pekerja yang dibutuhkan industri saat ini [3], sehingga unit pelatihan yang dikembangkan juga perlu memperhatikan kedua aspek tersebut.

Selain itu, unit pelatihan tersebut juga dapat menjadi sarana bagi dosen untuk melaksanakan pengabdian kepada masyarakat $(\mathrm{PkM})$ dengan menjadi instruktur pelatihan [4]. Berbekal dari pengalaman sebelumnya, perlu ada upaya agar unit yang dibentuk sesuai dengan kebutuhan. Metode pelaksanaan yang dilakukan dalam kegiatan pengabdian masyarakat ini antara lain studi literatur, pengumpulan data, analisa kebutuhan, perencanaan pembuatan unit pelatihan, dan pembuatan media promosi. Luaran lain dari program ini adalah terbentuknya dokumen kurikulum pelatihan dan bahan ajar yang sesuai dengan kompetensi SKKNI [5-7].

\section{METODE}

Metode pelaksanaan pengabdian masyarakat berupa pengembangan unit pelatihan di JTK Polban ini terdiri dari tiga tahap yang diilustrasikan pada Gambar 1 sebagai berikut:

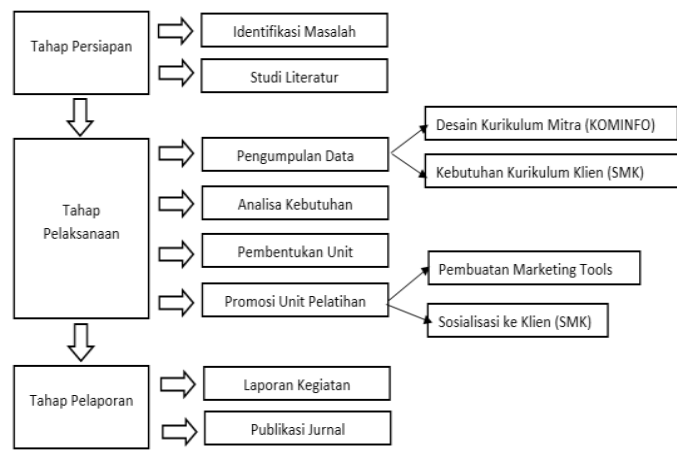

Gambar 1. Metode Pelaksanaan dan Evaluasi

\section{Tahap Persiapan}

\section{a. Identifikasi Masalah}

Sebagai tahap awal, hal yang perlu dilakukan adalah mengidentifikasi masalah yang ada pada mitra berdasarkan kegiatan yang telah dilakukan sebelumnya. Permasalahan yang muncul diantaranya adalah kebutuhan kurikulum pelatihan yang belum sepenuhnya sesuai dengan ekpektasi klien, serta sosialisasi programnya belum efektif dimana target peserta belum terpenuhi $100 \%$. JTK Polban memiliki kemampuan untuk mendukung program mitra agar pelaksanaan kedepan menjadi lebih baik. Dalam hal ini pula terdapat potensi untuk 
membentuk unit pelatihan yang dapat memenuhi ekpektasi klien serta menyiapkannya dalam mengikuti sertifikasi keahlian yang mendukung industri 4.0.

\section{b. Studi Literatur}

Tahapan studi literatur yang dibutuhkan adalah mencari literatur dari buku, jurnal, atau artikel yang menjelaskan tentang situasi terkini dari permasalahan lulusan SMK, kompetensi SKKNI yang memuat kemampuan yang harus dimiliki oleh pekerja bersertifikasi, dan metode yang dapat dilakukan dalam mengembangkan unit pelatihan.

\section{Tahap Pelaksanaan}

\section{a. Pengumpulan Data}

Setelah mengetahui situasi terkini tingkat pengangguran terbuka dari BPS, observasi difokuskan kepada lulusan SMK. Kegiatan observasi ini dilakukan melalui pengumpulan data dari SMK bidang Teknik Komputer dan Jaringan (TKJ), Rekayasa Perangkat Lunak (RPL), dan Multimedia di wilayah Bandung dan Cimahi. Data yang dikumpulkan berupa profil lulusan SMK dan dokumen kurikulum yang digunakan.

\section{b. Analisa Kebutuhan}

Analisia kebutuhan adalah tahapan penting untuk mempersiapkan unit yang dapat memfasilitasi pelatihan. Adapun enam poin analisis yang harus dilakukan yaitu: (1) menganalisa kebutuhan klien di sejumlah SMK di wilayah Bandung dan Cimahi, (2) data SKKNI dari mitra,
(3) profil lulusan SMK yang belum sesuai dengan kompetensi SKKNI, (4) struktur unit yang dapat mendukung pelatihan sesuai standar SKKNI, (5) rencana kerja unit yang dapat mendukung pelatihan sesuai standar SKKNI, dan (6) penyusunan kurikulum pelatihan.

\section{Perencanaan Pembuatan Unit Pelatihan}

Dari hasil analisa, maka dibuatlah perancanaan unit pelatihan di JTK Polban. Selain itu, disusun pula kurikulum dan bahan ajar pelatihan sesuai hasil analisa. Terdapat tiga langkah perencanaan pembuatan unit ini yaitu: (1) rekonsiliasi profil lulusan SMK dengan SKKNI, (2) membuat struktur yang dapat mendukung pelatihan sesuai standar SKKNI dan (3) membuat rencana kerja yang dapat mendukung pelatihan sesuai standar SKKNI.

\section{Pembuatan Media Promosi}

Media promosi digunakan untuk mempromosikan kepada masyarakat khususnya lulusan SMK bahwa telah dibentuk unit pelatihan yang dapat meningkatkan keterampilan mereka di bidang teknologi informasi. Tahap ini dilakukan dengan mendesain marketing tools seperti flyer, poster, $x$-banner, dan spanduk yang dibutuhkan untuk memasarkan unit pelatihan. Selain itu dilakukan pula sosialisasi terkait unit pelatihan ini ke SMK-SMK terkait.

\section{Tahap Pelaporan}

Dalam tahapan pelaporan program pengabdian masyarakat ini terdiri dari 
DIFUSI

Volume 3, No.2 Juli 2020

tiga langkah yaitu: (1) menyusun laporan kegiatan berdasarkan hasil yang telah dilaksanakan, rencana pengembangan berikutnya, serta kesimpulan dan saran. (2) menyusun karya ilmiah yang dipublikasikan pada jurnal pengabdian masyarakat. (3) keberlanjutan program ini dilakukan dengan menyelenggarakan pelatihan-pelatihan menggunakan kurikulum dan bahan ajar yang telah disusun, serta evaluasi untuk perbaikan pada kegiatan yang akan datang.

\section{HASIL DAN PEMBAHASAN}

Metode pelaksanaan pengabdian kepada masyarakat sebagaimana yang telah dijelaskan pada bagian 2 memiliki tiga tahapan yaitu tahap persiapan, tahap pelaksanaan dan tahap pelaporan. Tahap persiapan telah dibahas pada bagian sebelumnya, adapun bagian ini akan memaparkan hasil pada tahap pelaksanaan dan tahap pelaporan.

\section{Tahap Pelaksanaan}

\section{a. Pengumpulan Data}

Untuk mendapatkan profil lulusan serta capaian pembelajaran SMK, tim PkM melakukan pengumpulan data ke beberapa SMK di Bandung dan Cimahi, SMK yang dikunjungi dapat dilihat pada Tabel 1.

Kegiatan pengumpulan data ini dilakukan melalui wawancara ke beberapa manajemen di SMK (ketua prodi/ketua tim kurikulum/ketua jurusan). SMK yang dijadikan tujuan dalam pengumpulan data ini adalah SMK yang sesuai dengan bidang unit pelatihan yang akan dibangun di JTK, yakni: Junior Mobile Pro- grammer (JMP), Junior Web Programmer (JWP), dan Junior Network Administrator (JNA).

Tabel 1. Data SMK di Bandung dan Cimahi yang dikunjungi

\begin{tabular}{|c|c|c|}
\hline No & Tujuan SMK & Alamat \\
\hline 1 & $\begin{array}{l}\text { SMKN } 4 \\
\text { Bandung }\end{array}$ & $\begin{array}{l}\text { J1. Kliningan No.6, } \\
\text { Turangga, Kec. } \\
\text { Lengkong, Kota } \\
\text { Bandung, Jawa Barat } \\
40264\end{array}$ \\
\hline 2 & $\begin{array}{l}\text { SMKN } 2 \\
\text { Bandung }\end{array}$ & $\begin{array}{l}\text { J1. Ciliwung No.4, } \\
\text { Cihapit, Kec. Bandung } \\
\text { Wetan, Kota Bandung, } \\
\text { Jawa Barat } 40114\end{array}$ \\
\hline 3 & $\begin{array}{l}\text { SMK } \\
\text { Prakarya } \\
\text { Internasional }\end{array}$ & $\begin{array}{l}\text { J1. Inhoftank Gg. } \\
\text { Tegallega No.46-146, } \\
\text { Pelindung Hewan, Kec. } \\
\text { Astanaanyar, Kota } \\
\text { Bandung, Jawa Barat } \\
40243\end{array}$ \\
\hline 4 & $\begin{array}{l}\text { SMK TI } \\
\text { Garuda } \\
\text { Cimahi }\end{array}$ & $\begin{array}{l}\text { J1. Sangkuriang No.30, } \\
\text { Cipageran, Kec. } \\
\text { Cimahi Utara, Kota } \\
\text { Cimahi, Jawa Barat } \\
40511\end{array}$ \\
\hline 5 & $\begin{array}{l}\text { SMK TI } \\
\text { Pembangunan } \\
\text { Cimahi }\end{array}$ & $\begin{array}{l}\text { J1. H. Bakar, Utama, } \\
\text { Kec. Cimahi Sel., Kota } \\
\text { Cimahi, Jawa Barat } \\
40521\end{array}$ \\
\hline 6 & $\begin{array}{l}\text { SMK } \\
\text { Angkasa } \\
\text { Bandung }\end{array}$ & $\begin{array}{l}\text { J1. LMU Subagio } \\
\text { No.22, Husen } \\
\text { Sastranegara, Kec. } \\
\text { Cicendo, Kota } \\
\text { Bandung, Jawa Barat } \\
40174\end{array}$ \\
\hline 7 & $\begin{array}{l}\text { SMKN } 2 \text { Ci- } \\
\text { mahi }\end{array}$ & $\begin{array}{l}\text { Jalan Kamarung No.69, } \\
\text { RT.2/RW.5, Citeureup, } \\
\text { Cimahi Utara, } \\
\text { Citeureup, Kec. Cimahi } \\
\text { Utara, Kota Cimahi, } \\
\text { Jawa Barat } 40512\end{array}$ \\
\hline
\end{tabular}

Data yang didapatkan dari kegiatan tersebut adalah profil lulusan SMK, dan kurikulum/silabus pada beberapa mata pelajaran yang terkait dengan bidang pelatihan. Pada kegiatan ini juga didiskusikan kesesuaian 
antara kurikulum SMK dengan SKKNI dari mitra. Beberapa foto pada kegiatan pengumpulan data dapat dilihat pada Gambar 2,

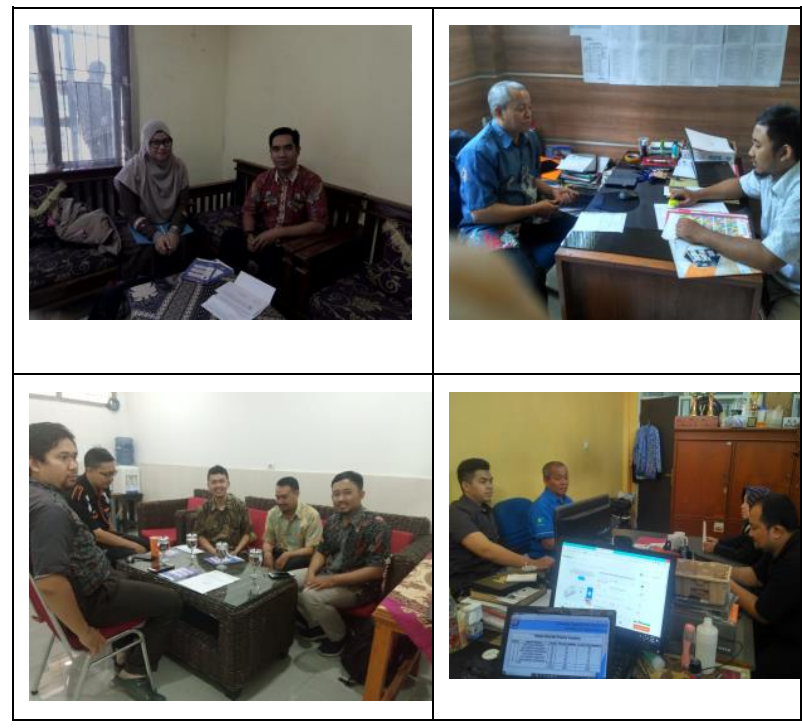

Gambar 1. Pengumpulan Data ke SMK

\section{b. Analisa Kebutuhan}

Untuk menentukan silabus dan bahan ajar pelatihan, maka dilakukan analisa terkait kompetensi lulusan SMK yang dilihat dari kurikulum dan silabus yang diajarkan di SMK. Kemudian menganalisa komparasi antara kurikulum pelatihan VSGA tahun 2019 dengan kurikulum SMK terkini. Hal ini dilakukan agar dapat diketahui apakah kompetensi lulusan SMK memiliki dasar pengetahuan yang cukup untuk melakukan pelatihan, ataukah justru mereka telah mendapatkan seluruh target materi pelatihan saat di SMK. Tabel 2 merupakan hasil dari analisa komparasi antara silabus pelatihan VSGA 2019 dan Silabus SMK untuk pelatihan Junior Mobile Programmer (JMP):
Tabel 1. Perbandingan SKKNI dan Kurikulum SMK bidang Mobile Programmer

\begin{tabular}{|c|c|c|}
\hline No & SKKNI & Kurikulum SMK \\
\hline 1 & $\begin{array}{l}\text { Menunjukkan je- } \\
\text { nis platform ope- } \\
\text { rating system dan } \\
\text { bahasa pemro- } \\
\text { graman di dalam } \\
\text { perangkat lunak }\end{array}$ & $\begin{array}{l}\text { Diajarkan pada } \\
\text { Mata Pelajaran } \\
\text { Sistem Kompu- } \\
\text { ter, Pemrogram- } \\
\text { an Dasar dan Pe- } \\
\text { mrograman Ber- } \\
\text { orientasi Objek }\end{array}$ \\
\hline 2 & $\begin{array}{l}\text { Merancang data- } \\
\text { base dan data per- } \\
\text { sistence pada mo- } \\
\text { bile data }\end{array}$ & $\begin{array}{l}\text { Diajarkan pada } \\
\text { Mata Pelajaran } \\
\text { Pemrograman } \\
\text { Perangkat Berge- } \\
\text { rak }\end{array}$ \\
\hline 3 & $\begin{array}{l}\text { Mampu menyu- } \\
\text { sun mobile loca- } \\
\text { tion based servi- } \\
\text { ce, GPS dan mo- } \\
\text { bile navigation }\end{array}$ & $\begin{array}{l}\text { Tidak terdapat } \\
\text { pada Silabus } \\
\text { SMK }\end{array}$ \\
\hline 4 & $\begin{array}{l}\text { Mampu meran- } \\
\text { cang mobile inter- } \\
\text { face }\end{array}$ & $\begin{array}{l}\text { Diajarkan pada } \\
\text { Mata Pelajaran } \\
\text { Pemrograman } \\
\text { Perangkat Berge- } \\
\text { rak }\end{array}$ \\
\hline 5 & $\begin{array}{l}\text { Mampu menjelas- } \\
\text { kan dasar-dasar } \\
\text { mobile security }\end{array}$ & $\begin{array}{l}\text { Tidak terdapat } \\
\text { pada Silabus } \\
\text { SMK }\end{array}$ \\
\hline 6 & $\begin{array}{l}\text { Mampu menun- } \\
\text { jukkan mobile } \\
\text { sensor dan spesi- } \\
\text { fikasi teknisnya } \\
\text { untuk mobile } \\
\text { computing }\end{array}$ & $\begin{array}{l}\text { Tidak terdapat } \\
\text { pada Silabus } \\
\text { SMK }\end{array}$ \\
\hline 7 & $\begin{array}{l}\text { Mampu menentu- } \\
\text { kan mobile seluler } \\
\text { network }\end{array}$ & $\begin{array}{l}\text { Tidak terdapat } \\
\text { pada Silabus } \\
\text { SMK }\end{array}$ \\
\hline
\end{tabular}

Untuk pelatihan Junior Mobile Programmer (JMP), secara khusus, di SMK sudah terdapat mata pelajaran yang membahas kompetensi tersebut, yaitu pada mata pelajaran Pemrograman Perangkat Bergerak (Kurikulum 2013) atau Pemrograman Web dan Perangkat Bergerak (Kurikulum Nasional). Namun terdapat pula beberapa target materi 
pelatihan yang belum diajarkan di SMK, tentunya hal ini akan menjadi tantangan tersendiri dalam menyiapkan konten bahan ajarnya. Sedangkan untuk Junior Web Programmer (JWP), berikut ini adalah hasil analisa komparasi antara silabus pelatihan VSGA 2019 dan Silabus SMK sebagaimana tertuang pada Tabel 3.

Untuk pelatihan Junior Web Programmer (JWP), di SMK sudah terdapat mata pelajaran yang mengajarkan kompetensi tersebut, yaitu pada mata pelajaran Pemrograman Web (Kurikulum 2013), Pemrograman Web Dinamis (kurikulum 2013) serta Pemrograman Web dan Perangkat Bergerak (Kurikulum Nasional). Semua materi pelatihan ini telah diajarkan semua di SMK, bahkan terdapat materi yang lebih dalam seperti penggunaan framework dalam pemrograman web. Hal ini pun tentu menjadi tantangan dalam menyusun bahan ajar agar para lulusan SMK ketika melakukan pelatihan tetap mendapatkan ilmu atau teknik yang baru. Kemudian pada bidang Junior Network Administrator (JNA). Tabel 4 adalah hasil analisa komparasi antara silabus pelatihan VSGA 2019 dan Silabus SMK.

Untuk pelatihan Junior Network Administrator (JNA), di SMK sudah terdapat mata pelajaran yang mengajarkan kompetensi tersebut, yaitu pada mata pelajaran Administrasi Sistem Jaringan (2013) atau Administrasi Infrastruktur Jaringan (Kurikulum Nasional). Pada dasarnya semua materi pelatihan ini telah diajarkan di SMK. Berbeda dengan pelatihan JMP dan JWP, pelatihan ini memerlukan alat dan bahan dalam pelaksanaan praktikum nya. Dari beberapa SMK yang didatangi, kendala yang dihadapi adalah ketersediaan alat dan bahan praktikum. Hal ini perlu disiasati juga dalam menyusun bahan ajar pelatihan selanjutnya, sehingga proses pelatihan benar-benar mampu mengimplementasikan materi pelatihan secara praktik.

Tabel 2. Perbandingan SKKNI dan Kurikulum SMK bidang Web Developer

\begin{tabular}{|c|c|c|}
\hline No & SKKNI & Kurikulum SMK \\
\hline 1 & Mengimplementasikan user interface & $\begin{array}{l}\text { Diajarkan pada Mata Pelajaran Pemro- } \\
\text { graman Web }\end{array}$ \\
\hline 2 & $\begin{array}{l}\text { Menerapkan perintah eksekusi bahasa pemro- } \\
\text { graman berbasis teks, grafik, dan multimedia }\end{array}$ & $\begin{array}{l}\text { Diajarkan pada Mata Pelajaran Pemro- } \\
\text { graman Web }\end{array}$ \\
\hline 3 & $\begin{array}{l}\text { Menyusun fungsi, file atau sumber daya pe- } \\
\text { mrograman yang lain dalam organisasi yang rapi }\end{array}$ & $\begin{array}{l}\text { Diajarkan pada Mata Pelajaran Pemro- } \\
\text { graman Web Dinamis }\end{array}$ \\
\hline 4 & $\begin{array}{l}\text { Menulis kode dengan prinsip sesuai guidelines dan } \\
\text { best practices }\end{array}$ & $\begin{array}{l}\text { Diajarkan pada Mata Pelajaran Pemro- } \\
\text { graman Web Dinamis }\end{array}$ \\
\hline 5 & Mengimplementasikan pemrograman terstruktur & $\begin{array}{l}\text { Diajarkan pada Mata Pelajaran Pemro- } \\
\text { graman Web Dinamis }\end{array}$ \\
\hline 6 & $\begin{array}{l}\text { Menggunakan Library atau Komponen Pre- } \\
\text { Existing }\end{array}$ & $\begin{array}{l}\text { Diajarkan pada Mata Pelajaran Pemro- } \\
\text { graman Web Dinamis }\end{array}$ \\
\hline 7 & Mengimplementasikan user interface & $\begin{array}{l}\text { Diajarkan pada Mata Pelajaran Pemro- } \\
\text { graman Web }\end{array}$ \\
\hline
\end{tabular}


DIFUSI

Volume 3, No.2 Juli 2020

Tabel 3. Perbandingan SKKNI dan Kurukulum SMK bidang Network Administrator

\begin{tabular}{lll}
\hline No & SKKNI & Kurikulum SMK \\
\hline 1 & Merancang pengalamatan jaringan & \\
2 & Memasang jaringan nirkabel & \\
3 & Mengkonfigurasi switch pada jaringan & $\begin{array}{l}\text { Diajarkan pada mata pelajaran Administrasi } \\
\text { Infrastruktur Jaringan }\end{array}$ \\
4 & $\begin{array}{l}\text { Mengkonfigurasi routing pada perangkat } \\
\text { jaringan dalam satu autonomous system }\end{array}$ & \\
5 & $\begin{array}{l}\text { Mengkonfigurasi routing pada perangkat } \\
\text { jaringan antar autonomous system }\end{array}$ & \\
6 & Merancang pengalamatan jaringan & \\
7 & Memasang jaringan nirkabel & \\
\hline
\end{tabular}

Selain melakukan analisa terhadap silabus materi pelatihan, data lain yang perlu dikumpulkan adalah profil lulusan SMK yang bekerja sesuai dengan bidangnya. Namun, terdapat kesulitan dalam mendapatkan data tersebut karena rata-rata tiap sekolah tidak memiliki data yang spesifik kemana lulusannya bekerja (belum adanya tracer study). Data yang dimiliki hanya sebatas prosentase lulusan yang bekerja, lulusan yang belum bekerja, dan lulusan yang melanjutkan ke perguruan tinggi.

Berdasarkan data-data yang telah didapatkan, langkah berikutnya adalah merumuskan dan menyusun silabus pelatihan dan bahan ajar yang difokuskan pada pendalaman materi fundamental serta materi praktikum. Untuk setiap pelatihannya, materi praktikum didesain dalam bentuk proyek untuk menyelesaikan suatu permasalahannya, dengan demikian pengetahuan peserta yang telah didapatkan di SMK disertai dengan materi pada pelatihan mampu meningkatkan keahlian mereka, sehingga dapat lebih terserap oleh industri. Tentunya silabus dan bahan ajar ini akan terus disempurnakan sesuai dengan perkembangan keilmuan dan teknologi yang dibutuhkan oleh industri 4.0.

Berdasarkan hasil analisa kebutuhan, maka dibentuklah unit pelatihan yang diberi nama Unit Pelatihan Teknologi Informasi (UPTI) di JTK Polban pada tiga bidang yaitu Junior Web Programmer (JWP), Junior Mobile Programmer (JMP), dan Junior Network Administrator (JNA). Tiap bidang terdiri dari 4 jam pelajaran pada setiap pertemuannya, dengan total 16 kali pertemuan materi, dan 2 kali pertemuan untuk persiapan ujian sertifikasi. Untuk dapat lulus dari pelatihan ini, peserta diwajibkan hadir minimal 16 kali dari 18 pertemuan yang sudah dijadwalkan serta lulus ujian sertifikasi.

\section{c. Perencanaan Pembentukan Unit Pelatihan}

Unit yang akan dibangun harus mengacu pada kebutuhan klien. Berdasarkan analisis kebutuhan, fokus utama unit ini adalah bidang pelatihan pada lingkup teknologi infor- 
masi. Adapun struktur organisasinya dapat dilihat pada Gambar 3.

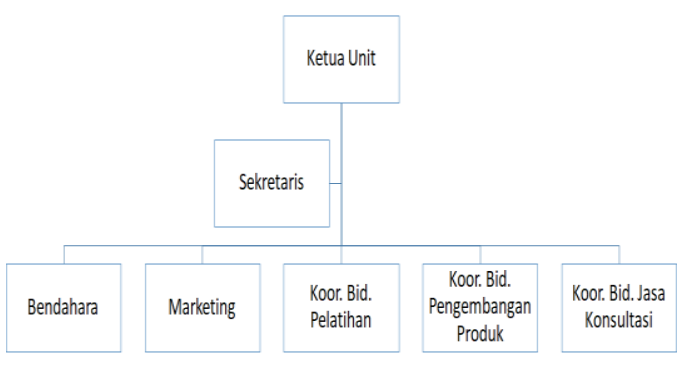

Gambar 2. Struktur organisasi unit pelatihan

Struktur organisasi terdiri dari ketua unit, sekretaris, bendahara, marketing, koordinator bidang pelatih an, koordinator bidang pengembangan produk, dan koordinator bidang jasa konsultasi. Khusus penyusunan kurikulum dan bahan ajar untuk pelatihan dilakukan oleh koordinator bidang pelatihan yang memiliki tugas pokok meliputi melakukan koordinasi dalam mempersiapkan, melaksanakan, dan mengevaluasi hal-hal yang terkait dengan program pelatihan pada unit ini serta membuat laporan program pelatihan di unit secara periodik. Gambar 4 adalah beberapa foto pada sekretariat unit pelatihan teknologi informasi di JTK.

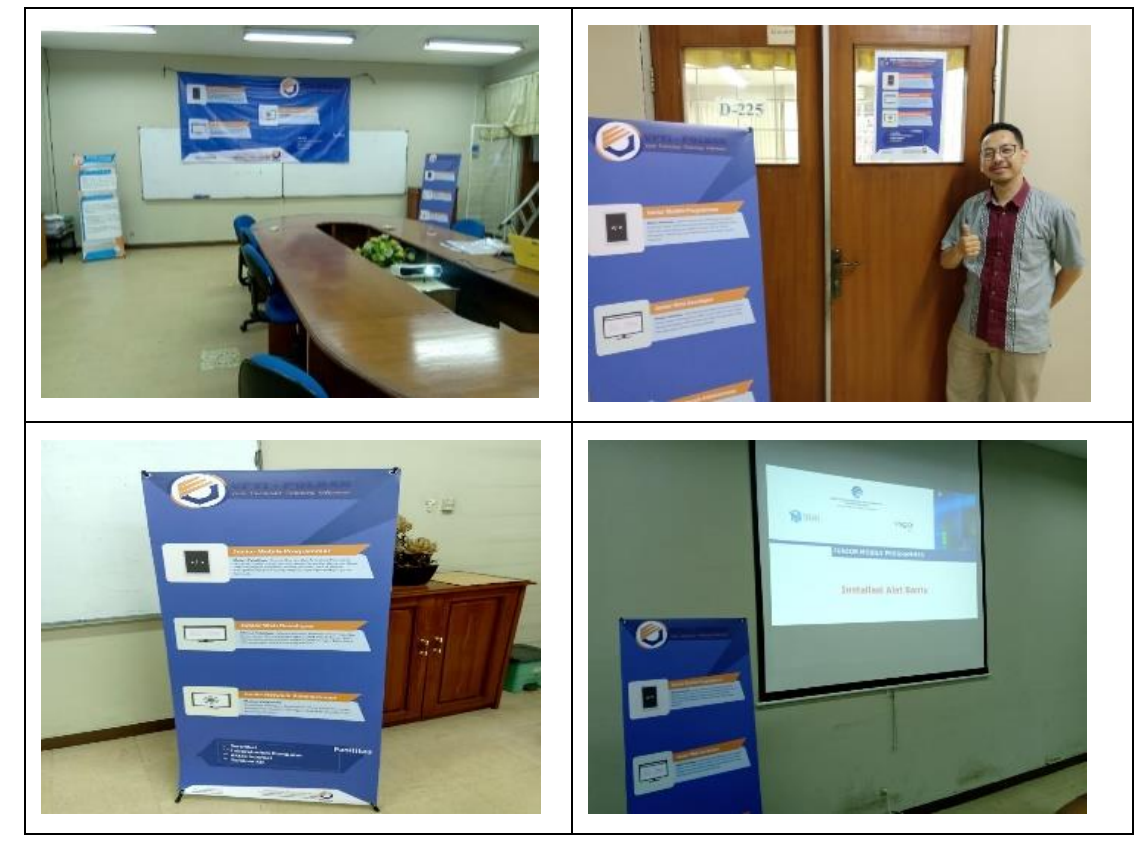

Gambar 3. Setup Ruangan Unit Pelatihan

\section{d. Promosi Unit Pelatihan}

Tahap ini dilakukan dengan mendesain marketing tools seperti flyer, poster, $x$-banner, dan spanduk yang dibutuhkan dalam memasarkan unit pelatihan. Selain itu dilakukan pula sosialisasi terkait unit pelatihan yang telah dibentuk ke SMK jurusan RPL dan TKJ di Kota Bandung dan Cimahi, yaitu SMKN 4 Bandung, SMK Prakarya Internasional, dan SMK Angkasa Bandung. Kunjungan dilakukan dalam rangka pengenalan Unit Pelatihan Teknolo- 
gi Informasi (UPTI) yang terdapat di JTK Polban. Target yang di kunjungi adalah Wakil Kepala Sekolah Bagian Kurikulum, Ketua Jurusan RPL dan TKJ serta Bagian Hubungan Industri di setiap Sekolah.

\section{Tahap Pelaporan}

Seluruh kegiatan yang berkaitan dengan PkM ini dilaporkan dalam dokumen laporan akhir pengabdian masyarakat Polban. Selain itu, sebagai salah satu luaran kegiatan yakni publikasi dalam bentuk karya ilmiah di jurnal pengabdian masyarakat. Setelah unit ini terbentuk, diharapkan keberlanjutan program dilakukan dengan menyelenggarakan pelatihan-pelatihan sesuai kurikulum dan bahan ajar yang telah disusun.

\section{KESIMPULAN}

Dari hasil kegiatan ini, disimpulkan sebagai berikut, Unit Pelatihan Teknologi Informasi (UPTI) JTK Polban sangat berpotensi untuk membantu permasalahan mitra dalam menyelaraskan kemampuan lulusan SMK sehingga dapat diterima di industri. Skema pelatihan yang dikembangkan adalah Junior Web Programmer (JWP), Junior Mobile Programmer (JMP), dan Junior Network Administrator (JNA). Berdasarkan data yang didapat, silabus dan bahan ajar untuk pelatihan telah disesuaikan dengan kompetensi lulusan SMK dan kompetensi SKKNI.

Dari hasil kegiatan Pengabdian kepada Masyarakat ini disarankan perlu adanya tindak lanjut dari Direktur Politeknik Negeri Polban untuk mengesahkan unit pelatihan ini agar dapat beroperasi secara resmi. Untuk menjamin keberlanjutan program ini, selanjutnya tim UPTI akan menindaklanjuti dengan mencari peluang kerjasama dengan pihak terkait (SMK) dan menentukan jenis pelatihan. Rencana selanjutnya adalah dengan secara kontinyu melakukan sosialisasi dan promosi secara luas, tidak hanya pelatihan untuk lulusan SMK saja akan tetapi juga untuk seluruh elemen masyarakat. Selain itu, unit ini pun diharapkan dapat menjadi wadah bagi para dosen JTK dalam melakukan kegiatan pengabdian masyarakat dalam bentuk pelatihan yang sesuai dengan kompetensinya.

\section{UCAPAN TERIMAKASIH}

Ucapan terimakasih disampaikan kepada Unit Penelitian dan Pengabdian Kepada Masyarakat (UPPM) Polban yang telah mensponsori kegiatan ini, sehingga dapat terlaksana dengan baik. Semoga unit pelatihan teknologi informasi (UPTI) yang dikembangkan akan menjadi wadah kegiatan pengabdian kepada masyarakat bagi dosen JTK Polban yang dapat bermanfaat bagi banyak pihak.

\section{REFERENSI}

[1] Badan Pusat Statistik, Februari 2019, "Tingkat Pengangguran Terbuka (TPT) sebesar 5,01 persen." https://www.bps.go.id/pressrelease/ 2019/05/06/1564/februari-2019tingkat-pengangguran-terbuka-tptsebesar-5-01-persen.html. Tanggal akses : 5 September 2019.

[2] L. Rahadian, "Skill Tak Sesuai, Suplai Tenaga Kerja Tak Terserap". Dikutip dari: https://ekono-mi.bis- 
nis.com/read/20190316/12/900380/ skill-tak-sesuai-suplai-tenaga-kerjatak-terserap. Tanggal akses : 2 September 2019.

[3] G. Matturro, F. Raschetti, dan C. Fontán, "Soft Skills in Software Development Teams A Survey of the Points of View of Team Leaders and Team Members," IEEE/ACM 8th International Workshop on Cooperative and Human Aspects of Software Engineering, 2015.

[4] Presiden Republik Indonesia, "Peraturan Pemerintah Nomor 17 Tahun 2010 Tentang Pengelolaan dan Penyelenggaraan Pendidikan: Presiden Republik Indonesia,” 2010.
[5] KEPMEN Naker No. 458 Tahun 2015, "SKKNI Kategori Informasi dan Komunikasi Golongan Pokok Kegiatan Jasa Informasi Bidang Mobile Computing," 2015, SKKNI 2015-458.

[6] KEPMEN Naker No. 282 Tahun 2016, "Programmer Komputer, SKKNI Sektor Teknologi Informasi dan Komunikasi Bidang Keahlian Programmer Komputer," 2016, SKKNI 2016-282.

[7] KEPMEN Naker No. 82 Tahun 2017, "SKKNI Kategori Informasi dan Komunikasi Golongan Pokok Aktivitas Jasa Informasi Bidang Administrasi Sistem," 2017, SKKNI 2017-082. 